\title{
SPINAL ANAESTHESIA FOR A PATIENT WITH FIXED SPINE DEFORMITY
}

Ravindra C. G' ${ }^{1}$ Kiran $\mathrm{M}^{2}$, Chandrashekarappa $\mathrm{K}^{3}$, Ravindra G. $\mathrm{L}^{4}$

\section{HOW TO CITE THIS ARTICLE:}

Ravindra C. G, Kiran M, Chandrashekarappa K, Ravindra G. L. "Spinal Anaesthesia for a Patient with Fixed Spine Deformity". Journal of Evolution of Medical and Dental Sciences 2014; Vol. 3, Issue 11, March 17;

Page: 2836-2839, DOI: $10.14260 /$ jemds/2014/2214

ABSTRACT: Kyphoscoliosis is forward and lateral bending of the spine commonly affecting the dorsal and lumbar spine. It usually develops due to tuberculosis in developing countries. Use of neuraxial block in a patient with severe kyphoscoliosis is controversial. We describe the anaesthetic management by spinal anaesthesia of a patient with severe kyphosis for cystolithotomy. The perioperative course was uneventful.

KEYWORDS: Spinal anaesthesia, Kyphosis, Cystolithotomy.

CASE REPORT \& CASE HISTORY: A 40 year male patient was posted for vesicular stone removal. The patient gives history of difficulty in micturition from 15 days and retention of urine of one day. The patient also gives h/o productive cough. Patient had thoracic kyphosis which he developed after the age of 20 years. Patient was unable to lie down on his back and could only lie down only on his side. There was no history of any motor or sensory symptoms or any bowel disturbance. On examination, general condition was poor with moderate built and poor nourishment. He had severe pallor with grade 3 clubbing. Coarse crepitations were heard all over lung field. The patient developed grade 3 dyspnea on minimal exertion. His investigations are as follows:

\begin{tabular}{|l|l|}
\hline Hemoglobin & $\begin{array}{l}6.7 \mathrm{gm} . \% \\
12.2 \mathrm{gm} . \% \text { after treatment }\end{array}$ \\
\hline Total count & $4200 \mathrm{cells} / \mathrm{cmm}$ \\
\hline Eosinophil count & $29 \%$ \\
\hline U S G & $1.8 \mathrm{~cm} \mathrm{x} 1.5 \mathrm{~cm}$ stone in the urinary bladder \\
\hline P F T & Restrictive lung disease \\
\hline Blood urea & $21 \mathrm{mg} / \mathrm{dl}$ \\
\hline Serum creatinine & $0.78 \mathrm{mg} / \mathrm{dl}$ \\
\hline Random blood sugar & $70 \mathrm{mg} / \mathrm{dl}$ \\
\hline
\end{tabular}

The case was deferred as the physical condition of the patient was poor. The patient was posted for surgery after 4 units blood transfusion and antibiotics, nebulization, physiotherapy and bronchodilators for the pulmonary infection.

ANAESTHETIC MANAGEMENT: The patient and his relatives were counseled about the risks involved due to anaesthesia. The possibility of difficulty in spinal or epidural anaesthesia, inadequate level of block during regional anaesthesia, difficulty in ventilation and intubation during general anaesthesia and possibility of requirement of post-operative mechanical ventilation in ICU were discussed with them. Special back supports were prepared and the patient was made to lie down to find see his level of comfort and the surgical site exposure. With both surgeon and the patient satisfied, high risk consent was taken from the patient and the relatives. 
The patient was shifted to operation theatre and made to lie down on the specially prepared back support. 5 leads ECG, $\mathrm{SPO}_{2}$, NIBP and temperature monitor were connected. Oxygen was supplemented using a face mask@4lts/ min. 500ml of ringer lactate was given as preload. Emergency airway cart was kept stand by.

Using a 25G Quincke spinal needle, spinal was given in left lateral position with $5^{0}$ head down tilt at the level of L3-L4 and $15 \mathrm{mg}$ of heavy Bupivacaine was given on the $3^{\text {rd }}$ attempt. Left lateral position was retained for 15 mins as the patient could not lie down flat after which the patient was made lie supine on the back support. Oxygen supplementation was continued. $\mathrm{T}_{6}$ level of sensory block was achieved. The patient was sedated with Inj midazolam $1 \mathrm{mg}$. During surgery the patient developed hypotension which was treated with $6 \mathrm{mg}$ of Inj mephentramine. The procedure took about 45 mins. After the procedure, the patient was shifted to recovery room \& then to the postoperative ward after 2 segment regression of anaesthesia. Analgesia was maintained with Inj diclofenac $75 \mathrm{mg}$.

DISCUSSION: Kyphosis is an exaggerated anterior flexion of spine resulting in round or hunch back appearance ${ }^{1}$. Causes of thoracic and thoracolumbar kyphosis are osteoporosis, Scheuermann's disease, post traumatic kyphosis, post infection kyphosis, paralytic kyphosis ${ }^{2}$ etc. Kyphosis is usually associated scoliosis. A patient with kyphosis posted for spine correction surgery or non-spine surgery pose multiple challenges.

Active chest infection, dyspnea on minimal exertion and anaemia indicated a poor respiratory reserve. A course of antibiotic, bronchodilators, nebulization and good physiotherapy with chest exercise along with blood transfusion helped to reduce the pulmonary infection and improve pulmonary reserves. Though the patient had good mouth opening of more than 3 fingers width and a good neck flexion and extension, as the patient was not able to lie supine, it could results in a difficult airway. So a difficult airway cart with orophayrngeal airway, laryngeal mask airways, McCoy blade no $3 \& 4$ with short handle, cricothyroidotomy needle with jet ventilator and surgical kit for tracheostomy was prepared with an ENT surgeon on call.

Multiple organ systems are deranged. Abnormal rib cage and crowding of rib results in restrictive type of lung disease. Spinal angle of more than $40^{\circ}$ at thoracic level results in progressive cardiac and pulmonary failure as reported by Weinstein and colleague. The compliance of the lung decreases with increase in work of breathing. Tidal volume, vital capacity and total lung capacity are reduced in PFT. Chronic hypoxemia results in cor pulmonary33. Echocardiography shows pulmonary hypertension and right ventricular hypertrophy. Incidence of pulmonary infection is high due to poor cough reflex ${ }^{4}$.

Positive pressure ventilation decreases venous return and along with negative inotropic effect of anesthetic agents can lead to severe decrease in blood pressure. Coughing and bucking at the end of the surgery may transiently but significantly decreases functional residual capacity, resulting in further ventilation perfusion mismatch and hypoxemia5. The abnormal spine makes intubation and ventilation difficult. Co-existing hypoxemia and pulmonary infection may lead to difficult extubation and prolonged ventilation due to difficulty in aligning the airway. Postoperatively after general anaesthesia, elements of laryngeal incompetence and impaired swallowing further decrease the airway defense mechanisms. All these factors together can lead to delay in extubation and need for postoperative ventilation ${ }^{6}$. The risk of malignant hyperthermia in kyphoscoliosis patient cannot be 
undermined with susceptible agents like succinyl choline or halothane. Thus general anaesthesia (GA) can be difficult choice.

Regional anaesthesia is also difficult in patients with kyphotic spine. Difficulty in patient's positioning, identifying the landmarks and obliterated interspinous gap, makes spinal and epidural anaesthesia is technically difficult. The CSF volume is decreased in kyphotic spine, thus even lower doses of local anaesthetics may achieve higher than expected level of block resulting in higher incidence of hypotension. ${ }^{7}$ The volume of local anaesthetic must be accordingly adjusted. Bupivacaine dose was reduced to $15 \mathrm{mg}$. Even with this reduced dosage, the patient developed hypotension. There are reports that in patients with severe curves, hyperbaric solution may pool in the dependent portion of the spine and results in inadequate block. ${ }^{8}$ Caution must be advised with regional anaesthesia as neurological anomalies may associate with spinal abnormalities. The conventional dose of local anaesthetic causes higher block. Combined spinal epidural (CSE) technique is a good alternative. It offers rapid onset and safety from of toxic effects (due to decreased local anaesthetic dosage) combined with potential for improving an inadequate block and prolonging duration of anesthesia intraoperatively and analgesia post operatively. ${ }^{9}$ This technique reduces or eliminates some of the disadvantages of spinal anaesthesia while preserving their advantages.

Anesthesia inpatient with kyphosis poses a significant risk and there is no single regimen that can be recommended for anesthetic management for all cases. The location of surgery primarily determines the type of anaesthesia. General Anaesthesia can be associated with difficult intubation and prolonged post-operative ventilation. Epidural anaesthesia may not always give adequate level of block. Spinal anaesthesia ${ }^{10}$ and combined spinal anaesthesia ${ }^{11}$ are better option. Preparations for emergency airway must be made before hand to avoid any mishap. The success of the procedure here depended on the co-operation of the patient, surgeon and a good preparation of the patient and well prepared anaesthesia team.

\section{REFERENCES:}

1. Micheal K Urban and SalimLohlou. Muscle diseases, Anaesthesia and uncommon disease, $5^{\text {th }}$ ed. Lee A Fleisher; 144-145, 2009.

2. Rothman SimonE. The Spine, Pediatric kyphosis: Scheuermann's disease and congenital deformity, $5^{\text {th }}$ ed, vol 1, Saunders Elsevier; 2006.

3. Miller R D: Miller's Anaesthesia. Anaesthesia for orthopedic surgery, 6th ed Churchill Livingstone; p 2255-6, 2005.

4. J. J. Schwartz. Skin and musculoskeletal diseases, Anaesthesia and co-existing, $5^{\text {the }}$, Saunders Elsevier; p 505, 2010.

5. Bickler PE, Dueck R, Prutow RJ. Effects of barbiturate anaesthesia on functional residual capacity and ribcage/diaphragm contribution to ventilation, Anesthesiology. 1987; 66: 147148.

6. Baydur A, MilicEmili J. Respiratory mechanics in kyphoscoliosis. Monaldi Chest Diseases, 48(1): 69-79. 1993.

7. Klienman W, Mikhail M. Spinal, Epidural, and Caudal Blocks: Morgan G E, Mikhail S M, Murray M J, Clinical Anaesthesiology.4thed New York: McGraw Hill Inc; 289-323:2006

8. Moran DH, Johnson MD. Continuous spinal anaesthesia with combined hyperbaric and isobaric bupivacaine in a patient with scoliosis. Anesth Analg. 1990, 70:445. 
9. Holmstrom E, Laugaland K, Rawal N, Haliberg S. Combined spinal epidural block versus spinal and epidural block for orthopaedic surgery. Can J Anaesth; 1993, 10(7): 601-06.

10. Bansal N, Gupta S Anaesthetic management of a parturient with severe kyphoscoliosis, Kathmandu University Medical Journal), Vol. 6, No. 3, 2008, issue 23, 379-382.

11. Oksun Kim et al, Combined Spinal-epidural Anaesthesia in a Patient with Severe Thoracic Kyphoscoliosis, Korean J Anesthesiology, 2008, Vol. 54, 4.

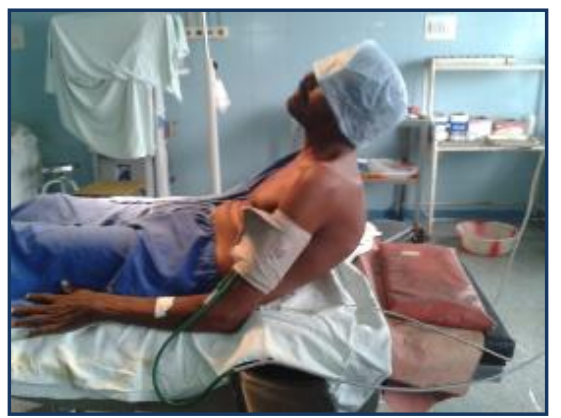

PATIENT SUPINE WITHOUT SUPPORT

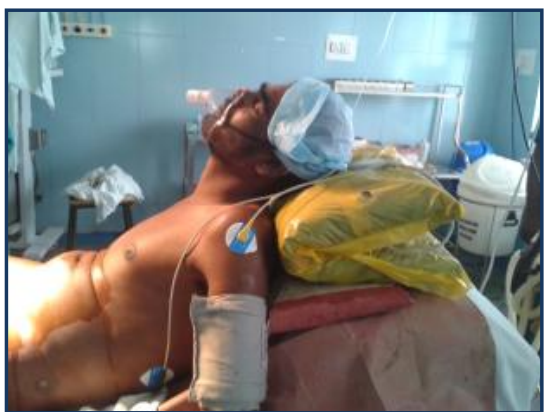

PATIENT LYING DOWN SUPINE WITH SUPPORT

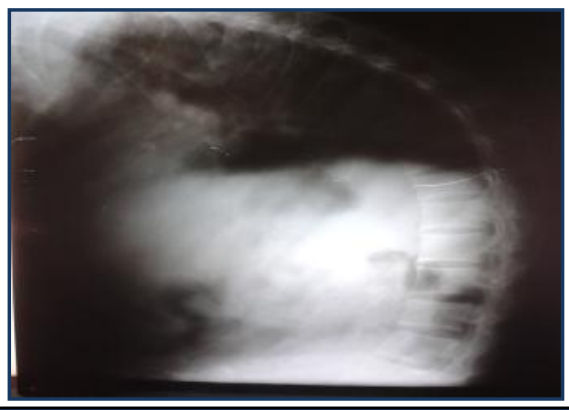

X RAY OF THE PATIENT SHOWING THORACIC KYPHOSIS

\section{AUTHORS:}

1. Ravindra C. G.

2. Kiran M.

3. Chandrashekarappa K.

4. Ravindra G. L.

\section{PARTICULARS OF CONTRIBUTORS:}

1. Assistant Professor, Department of Anaesthesia, Shimoga Institute of Medical Science, Shimoga.

2. Assistant Professor, Department of Anaesthesia, Shimoga Institute of Medical Science, Shimoga.

3. Associate Professor, Department of Anaesthesia, Shimoga Institute of Medical Science, Shimoga.
4. Professor and Head, Department of Anaesthesia, Shimoga Institute of Medical Science, Shimoga.

\section{NAME ADDRESS EMAIL ID OF THE CORRESPONDING AUTHOR:}

Dr. Kiran M, Assistant Professor, Department of Anaesthesia, Shimoga Institute of Medical Sciences, Shimoga.

E-mail: kiranm67@gmail.com

Date of Submission: 15/02/2014.

Date of Peer Review: 16/02/2014.

Date of Acceptance: 27/02/2014.

Date of Publishing: 12/03/2014. 